\title{
Model-Informed Precision Dosing during Infliximab Induction Therapy Reduces Variability in Exposure and Endoscopic Improvement between Patients with Ulcerative Colitis
}

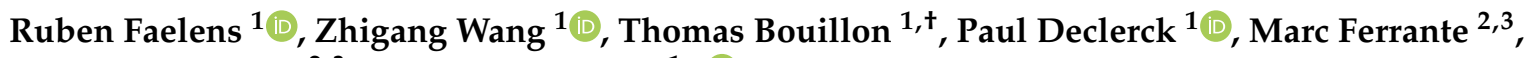 \\ Séverine Vermeire ${ }^{2,3}$ and Erwin Dreesen $1, * \mathbb{D}$ \\ 1 Department of Pharmaceutical and Pharmacological Sciences, Katholieke Universiteit Leuven, \\ 3000 Leuven, Belgium; ruben.faelens@kuleuven.be (R.F.); zhigang.wang@kuleuven.be (Z.W.); \\ thomas.bouillon@bionotus.com (T.B.); paul.declerck@kuleuven.be (P.D.) \\ 2 Department of Gastroenterology and Hepatology, University Hospitals Leuven, 3000 Leuven, Belgium; \\ marc.ferrante@uzleuven.be (M.F.); severine.vermeire@uzleuven.be (S.V.) \\ 3 Department of Chronic Diseases and Metabolism, Katholieke Universiteit Leuven, 3000 Leuven, Belgium \\ * Correspondence: erwin.dreesen@kuleuven.be; Tel.: +32-16-37-27-53 \\ + Current Address: BioNotus, 2845 Niel, Belgium.
}

check for updates

Citation: Faelens, R.; Wang, Z.;

Bouillon, T.; Declerck, P.; Ferrante, M.;

Vermeire, S.; Dreesen, E.

Model-Informed Precision Dosing

during Infliximab Induction Therapy

Reduces Variability in Exposure and

Endoscopic Improvement between

Patients with Ulcerative Colitis.

Pharmaceutics 2021, 13, 1623. https://

doi.org/10.3390/pharmaceutics13101623

Academic Editors: Jonás

Samuel Pérez-Blanco and José

Martínez Lanao

Received: 27 August 2021

Accepted: 27 September 2021

Published: 6 October 2021

Publisher's Note: MDPI stays neutral with regard to jurisdictional claims in published maps and institutional affiliations.

Copyright: (c) 2021 by the authors. Licensee MDPI, Basel, Switzerland. This article is an open access article distributed under the terms and conditions of the Creative Commons Attribution (CC BY) license (https:/ / creativecommons.org/licenses/by/ $4.0 /)$.
Abstract: Model-informed precision dosing (MIPD) may be a solution to therapeutic failure of infliximab for patients with ulcerative colitis (UC), as underexposure could be avoided, and the probability of endoscopic improvement (pEI; Mayo endoscopic subscore $\leq 1$ ) could be optimized. To investigate in silico whether this claim has merit, four induction dosing regimens were simulated: $5 \mathrm{mg} / \mathrm{kg}$ (label dosing), $10 \mathrm{mg} / \mathrm{kg}$, covariate-based MIPD (fat-free mass, corticosteroid use, and presence of extensive colitis at baseline), and concentration-based MIPD (based on the trough concentration at day 14). Covariate- and concentration-based MIPD were chosen to target the same median area under the infliximab concentration-time curve up to endoscopy at day $84\left(\mathrm{AUC}_{\mathrm{d} 84}\right)$, as was predicted from $10 \mathrm{mg} / \mathrm{kg}$ dosing. Dosing at $5 \mathrm{mg} / \mathrm{kg}$ resulted in a mean \pm standard deviation pEI of $55.7 \pm 9.0 \%$. Increasing the dose to $10 \mathrm{mg} / \mathrm{kg}$ was predicted to improve $\mathrm{pEI}$ to $65.1 \pm 6.1 \%$. Covariate-based MIPD reduced variability in exposure and pEI (65.1 $\pm 5.5 \%)$. Concentration-based MIPD decreased variability further $(66.0 \pm 3.9 \%)$ but did so at an increased average dose of $2293 \mathrm{mg}$ per patient, as compared to $2168 \mathrm{mg}$ for $10 \mathrm{mg} / \mathrm{kg}$ dosing. Mean $\mathrm{pEI}$ remained unchanged between $10 \mathrm{mg} / \mathrm{kg}$ dosing and MIPD, since the same median $\mathrm{AUC}_{\mathrm{d} 84}$ was targeted. In conclusion, quantitative simulations predict MIPD will reduce variability in exposure and pEI between patients with UC during infliximab induction therapy.

Keywords: infliximab; monoclonal antibody; ulcerative colitis; inflammatory bowel disease; endoscopy; population pharmacokinetics-pharmacodynamics; simulations; therapeutic drug monitoring; model-informed precision dosing

\section{Introduction}

Infliximab is a monoclonal antibody that binds and neutralizes the functional activity of tumor necrosis factor-alpha $(\mathrm{TNF} \alpha)$. Based on the results of the landmark Active Ulcerative Colitis Trials (ACT) 1 and 2, infliximab was approved for inducing and maintaining remission in patients with moderate-to-severe ulcerative colitis (UC) [1]. In these studies, endoscopic improvement (defined as a Mayo endoscopic subscore $\leq 1$ ) was achieved in about $60 \%$ of patients after administration of three infliximab infusions $(5 \mathrm{mg} / \mathrm{kg}$ body weight, at weeks 0,2 , and 6; endoscopy at week 8). In post-marketing studies, endoscopic improvement rates were lower (e.g., 47\% in Brandse et al. [2]), making unpredictable outcomes of infliximab induction therapy a challenge [2-5].

Dose finding in ACT 1 and 2 failed to show a consistent benefit of $10 \mathrm{mg} / \mathrm{kg}$ dosing over $5 \mathrm{mg} / \mathrm{kg}$ dosing [1]. However, higher infliximab serum concentrations during induc- 
tion therapy were found to correlate with short-term endoscopic improvement, as well as long-term relapse-free and colectomy-free survival [6]. To date, the infliximab exposureresponse relationship in patients with UC has been well-established [4,7-9]. Consequently, it has been hypothesized that targeting infliximab to a predefined "optimal" exposure has the potential to improve the response rate and identify primary non-responders (defined as non-response despite optimal infliximab exposure) $[2,10,11]$. To date, most therapeutic drug monitoring (TDM) studies of infliximab focus on maintenance therapy, whereas induction therapy is relatively unexplored. Moreover, the utility of TDM of infliximab in patients with UC remains controversial because of poor evidence from prospective TDM studies [10,12-14]. One potential reason for the weak evidence can be the use of inefficient TDM algorithms (analogous flowcharts and decision trees) in these TDM studies [15]. Therefore, model-informed precision dosing (MIPD), a more efficient and precise dose optimization strategy as compared to analogous TDM, has been suggested as a way out of this dilemma $[15,16]$.

MIPD can be implemented through either a priori or a posteriori dose optimization, both utilizing a population pharmacokinetic (popPK) model that serves as a prior. A priori dose optimization is done by involving patient's covariates/characteristics that explain between- and within-subject variability, while a posteriori dose optimization (Bayesian forecasting) is based on previous infliximab serum concentration measurements [17]. Through these two approaches, the MIPD software tool can recommend a dose that facilitates attainment of the therapeutic target exposure. Patient covariates such as C-reactive protein (CRP), serum albumin, antibodies to infliximab (ATI), body weight or fat-free mass, and fecal calprotectin have previously been identified in popPK modeling studies $[9,18]$.

In a previous popPK and exposure-response modeling analysis, we identified the relation between the area under the infliximab concentration-time curve up to endoscopy at day $84\left(\mathrm{AUC}_{\mathrm{d} 84}\right)$ and the probability of endoscopic improvement at day 84 [18]. Based on these results, we suggested that increased exposures would result in better clinical outcomes. We further suggested that any increased drug consumption may be offset through the use of MIPD. In the present work, we investigated these claims further by performing population simulations of these different dosing scenarios and comparing exposures, probability of endoscopic improvement, and average drug consumption.

\section{Materials and Methods}

\subsection{Population Pharmacokinetic and Exposure-Response Models}

A previously published one-compartment popPK model with interindividual and interoccasion variability was used to simulate infliximab exposure [18]. This model was built on a total of 583 samples from 204 patients with UC, and included C-reactive protein (CRP), serum albumin, and fat-free mass (FFM) as time-varying covariates, and Mayo endoscopic subscore, presence of extensive colitis, and corticosteroid use as baseline covariates.

Even though dose proportionality applies, when administering a higher dose of infliximab ( $c f$. Section 2.3. Dosing Scenarios), a more positive disease evolution is expected, thereby influencing the time-course of CRP and serum albumin, both acute phase proteins, and possibly fat-free mass as well. Since the original dataset used for popPK model building did not include patients on higher infliximab doses (cf. Section 2.2 Virtual Population), and to avoid bias in the scenarios with higher dosing, we chose to re-estimate the model without these covariates. In theory, this should increase the unexplained interoccasion variability and residual error instead.

The logistic regression exposure-response model was adapted as well. The model was built on a subset of 159 patients and fitted the original data well [18]. However, this model predicted an ever-increasing probability of endoscopic improvement with increasing infliximab exposure. This could not be reconciled with the current line of thinking for infliximab treatment in UC, which assumes the existence of intrinsic non-responders [19]. The model was adapted to introduce maximum transition probabilities $\mathrm{E}_{\max , 3 \rightarrow 2}$ and $E_{\max , 2 \rightarrow 1 / 0}$ for transitioning from a severe disease state (Mayo endoscopic subscore 3) to 
a moderate disease state (Mayo endoscopic subscore 2) and from a moderate disease state to endoscopic improvement (Mayo endoscopic subscore 1 or 0), respectively. Likelihood profiling was performed to identify the confidence bound for these parameters [20]. These $\mathrm{E}_{\text {max }}$ parameters were varied across a wide range of values and the associated $\mathrm{AUC}_{50} \mathrm{~s}$ (i.e., the infliximab exposures required to achieve half-maximal transition probabilities) were estimated, yielding a log-likelihood (LL) estimate for each parameter set. Estimates with $\triangle 2 L L=3.84$ showed the lower $95 \%$ confidence bound for the exposure-response model. These parameter estimates were then used for subsequent simulations.

\subsection{Virtual Population}

To construct the virtual population for the dosing simulations, the original clinical dataset was used [7]. Only patients with a baseline Mayo endoscopic subscore of 2 or 3 were included, resulting in a source dataset of 194 patients. This dataset was expanded through Monte Carlo sampling of interindividual variability (200 samples per individual patient), yielding a total of 38,800 virtual patients.

Baseline covariates were collected in a study conducted in accordance with the principles of good clinical practice and the Declaration of Helsinki. All patients provided written informed consent prior to participation in the Ethics Committee-approved IBD Biobank [B322201213950/S53684], whereby patients' characteristics and samples were collected prospectively on a series of predefined time points.

\subsection{Dosing Scenarios}

Four distinct dosing scenarios were evaluated. First, a standard dosing regimen of $5 \mathrm{mg} / \mathrm{kg}$ at days 0,14 , and 42 was applied to all virtual patients. Based on the exposureresponse analysis of the original dataset, there was support for a higher dose [18]. Therefore, $10 \mathrm{mg} / \mathrm{kg}$ was evaluated as a second dosing scenario.

We aimed for covariate-based and concentration-based MIPD to result in the same mean predicted probability of endoscopic improvement as in the $10 \mathrm{mg} / \mathrm{kg}$ dosing scenario. Therefore, MIPD scenarios were designed to target the same median AUC $_{\mathrm{d} 84}$ as was predicted from the $10 \mathrm{mg} / \mathrm{kg}$ dosing scenario. The third dosing scenario was purely based on the covariates (a priori MIPD). The popPK model was used to determine the covariatebased dose required to hit the exposure target associated with the predefined probability of endoscopic improvement.

Finally, Bayesian forecasting (a posteriori MIPD) was evaluated as a fourth dosing scenario. The first dose was the same as in the covariate-based MIPD scenario. The sampled interindividual variability was used to simulate the trough concentration on day 14 resulting from the covariate-based first dose. Residual error was sampled and added to this concentration. This simulated concentration was subsequently used to perform an empirical Bayesian estimation of the patient's individual PK parameters. These individual estimates were then used to adapt the subsequent doses at days 14 and 42 . Both doses were adapted to the same value, predicted to result in an $\mathrm{AUC}_{\mathrm{d} 84}$ exposure metric resulting in the target probability of endoscopic improvement.

\subsection{Evaluation of Dosing Scenarios}

The mean dose per patient and resulting exposures $\left(\mathrm{AUC}_{\mathrm{d} 84}\right)$ in each scenario were evaluated graphically as density plots. To quantify efficacy, the mean probability of endoscopic improvement was evaluated, as this reflects the expected fraction of patients attaining endoscopic improvement. Additionally, the mean overall dose per patient was evaluated. Finally, a robustness analysis was performed to determine whether our conclusions hold for other $E_{\max }$ parameter values.

\subsection{Software}

The adapted popPK and exposure-response models were estimated using NONMEM (version 7.4.3; Icon Development Solutions, Gaithersburg, MD, USA). Simulation of the 
dosing scenarios was performed using $\mathrm{R}$ (version 4.0.2; R Foundation for Statistical Computing, R Core Team, Vienna, Austria) with RxODE [21] and tdmore. The tdmore R package was developed at KU Leuven to perform simulation and evaluation of MIPD. It is available as open-source at github.com/tdmore-dev/tdmore (accessed on 27 August 2021). The NONMEM code and tdmore $\mathrm{R}$ code are provided in the Supplementary File.

\section{Results}

\subsection{Population Pharmacokinetic and Exposure-Response Models}

The popPK model was adapted to include only covariates at baseline. As expected, the interindividual variability on the elimination rate constant and the proportional residual error increased (Table S1, Supplementary Material). A visual predictive check of the updated popPK model is available in Figure S1.

Likelihood profiling of the exposure-response model showed a wide range of probable $\mathrm{E}_{\max , 3 \rightarrow 2}-\mathrm{E}_{\max , 2 \rightarrow 1 / 0}$ pairs. In Figure $\mathrm{S} 2$, the likelihood profile is shown for different parameter combinations. The $\Delta 2 \mathrm{LL}=3.84$ contour line in red shows parameter combinations limits for $E_{\max , 3 \rightarrow 2}-E_{\max , 2 \rightarrow 1 / 0}$ of either $92.6-100 \%$ or $100-78.4 \%$. Figure 1 shows the simulated PD model at parameter estimates with associated $\triangle 2 \mathrm{LL}=3.84$. Based on this plot, $\mathrm{E}_{\max , 2 \rightarrow 1 / 0}=78.4 \% / \mathrm{E}_{\max , 3 \rightarrow 2}=100 \%$ was selected for further simulations, as the most "pessimistic" scenario. The remainder of the possible parameter values were explored in the sensitivity analysis.

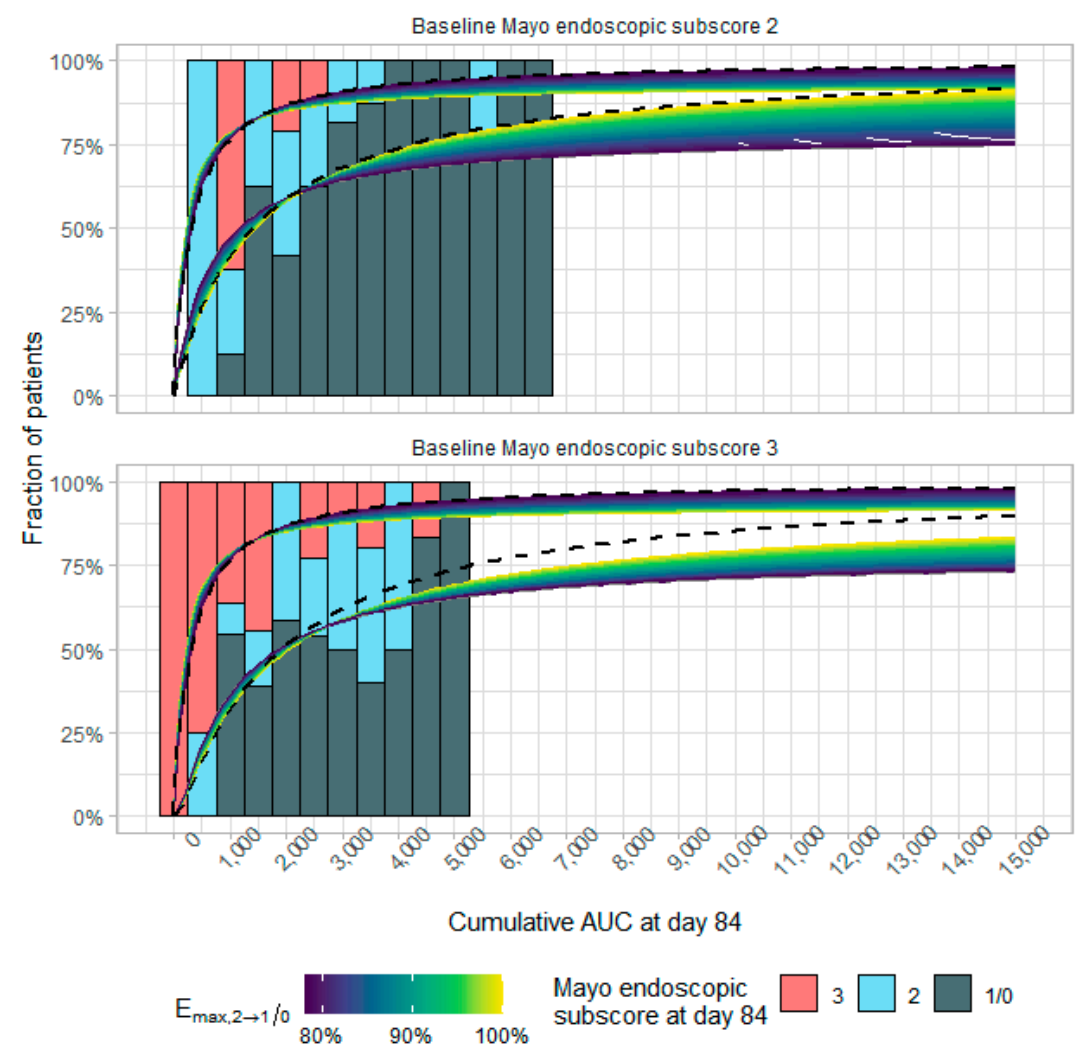

Figure 1. Exposure-response dataset (bars), binned per cumulative area under the curve (AUC) at day 84 and categorized according to Mayo endoscopic subscore at day 84 , and corresponding simulated exposure-response models (lines representing the fraction of patients achieving a Mayo endoscopic subscore $\leq 1$ [lower line] and $\leq 2$ [upper line]). The original exposure-response model of Dreesen et al. [18] is shown as a black dashed line $\left(E_{\max , 3 \rightarrow 2}\right.$ and $E_{\max , 2 \rightarrow 0 / 1}$ are both 100\%). Colored lines represent models at $\Delta 2 \mathrm{LL}=3.84$ with $\mathrm{E}_{\max , 3 \rightarrow 2} 93 \%$ and different $\mathrm{E}_{\max , 2 \rightarrow 1 / 0}$ values. All presented models fit the exposure-response dataset equally well (at $\alpha=0.05$ ) but have different predictions outside the observed exposure range. 


\subsection{Dosing Simulations: Exposure and Efficacy}

Simulation results are summarized in Table 1 and will be presented hereafter as median $\left[95 \%\right.$ prediction interval] for exposure $\left(\mathrm{AUC}_{\mathrm{d} 84}\right)$ and mean \pm standard deviation for probability of endoscopic improvement. As exposure and efficacy targets differ depending on the baseline endoscopic disease severity, results are reported for baseline Mayo endoscopic subscores of 2 (moderate disease severity; reported first) and 3 (high disease severity; reported second), separately. Exposures and associated probabilities of endoscopic improvement are shown in Figures 2 and 3.

Table 1. Summary of the simulation results.

\begin{tabular}{|c|c|c|c|c|c|c|c|}
\hline \multirow[b]{2}{*}{$\begin{array}{c}\text { Baseline Mayo } \\
\text { Endoscopic Subscore }\end{array}$} & \multirow[b]{2}{*}{ Dosing scenario } & \multicolumn{2}{|c|}{$\mathrm{AUC}_{\mathrm{d} 84}(\mathrm{mg} / \mathrm{L} \times \mathrm{Day})$} & \multicolumn{2}{|c|}{ pEI (\%) } & \multicolumn{2}{|c|}{$\begin{array}{c}\text { Cumulative Dose } \\
\text { (mg) }\end{array}$} \\
\hline & & median & {$[90 \% \mathrm{PI}]$} & mean & $\pm \mathrm{sd}$ & mean & $\pm \mathrm{sd}$ \\
\hline \multirow{4}{*}{2} & \multirow{4}{*}{$\begin{array}{c}5 \mathrm{mg} / \mathrm{kg} \\
10 \mathrm{mg} / \mathrm{kg} \\
\text { Covariate-based MIPD } \\
\text { Concentration-based } \\
\text { MIPD }\end{array}$} & 2455 & [1215-4805] & 61.2 & \pm 5.51 & 1090 & \pm 196 \\
\hline & & 4910 & [2431-9609] & 68.6 & \pm 3.60 & 2181 & \pm 393 \\
\hline & & 4895 & [2661-8522] & 68.7 & \pm 3.08 & 2166 & \pm 443 \\
\hline & & 5095 & [3683-6879] & 69.3 & \pm 1.67 & 2298 & \pm 613 \\
\hline \multirow{4}{*}{3} & \multirow{4}{*}{$\begin{array}{c}5 \mathrm{mg} / \mathrm{kg} \\
10 \mathrm{mg} / \mathrm{kg} \\
\text { Covariate-based MIPD } \\
\text { Concentration-based } \\
\text { MIPD }\end{array}$} & 1979 & [953-3990] & 50.3 & \pm 8.36 & 1078 & \pm 214 \\
\hline & & 3958 & [1906-7981] & 61.6 & \pm 6.05 & 2155 & \pm 428 \\
\hline & & 3933 & [2123-7045] & 61.7 & \pm 5.06 & 2137 & \pm 417 \\
\hline & & 4125 & [3056-5431] & 62.8 & \pm 2.51 & 2287 & \pm 643 \\
\hline \multirow{4}{*}{$\begin{array}{c}\text { Combined } \\
(2: 3 ; 49 \%: 51 \%)\end{array}$} & \multirow{4}{*}{$\begin{array}{c}5 \mathrm{mg} / \mathrm{kg} \\
10 \mathrm{mg} / \mathrm{kg} \\
\text { Covariate-based MIPD } \\
\text { Concentration-based } \\
\text { MIPD }\end{array}$} & 2210 & [1049-4448] & 55.7 & \pm 8.96 & 1084 & \pm 205 \\
\hline & & 4419 & [2098-8895] & 65.1 & \pm 6.11 & 2168 & \pm 411 \\
\hline & & 4372 & [2302-7940] & 65.1 & \pm 5.46 & 2151 & \pm 431 \\
\hline & & 4561 & [3209-6516] & 66.0 & \pm 3.91 & 2293 & \pm 628 \\
\hline
\end{tabular}

The systematically lower exposure at a baseline Mayo endoscopic subscore of 3 (severely active ulcerative colitis), as compared to a baseline Mayo endoscopic subscore of 2 (moderately active ulcerative colitis), may mechanistically be explained by a higher target load (targetmediated drug disposition) and protein-losing enteropathy (fecal drug loss). $\mathrm{AUC}_{\mathrm{d} 84}$, the area under the infliximab concentration-time curve from baseline up to endoscopy at day 84 (week 12); MIPD, model-informed precision dosing; pEI, probability of endoscopic improvement; PI, prediction interval; q, quantile; sd, standard deviation.

The $5 \mathrm{mg} / \mathrm{kg}$ dosing scenario resulted in an $\mathrm{AUC}_{\mathrm{d} 84}$ of 2455 [1215-4805] $\mathrm{mg} \times$ day/L and 1979 [953-3990] $\mathrm{mg} \times$ day/L, for baseline Mayo endoscopic subscore 2 and 3, respectively. This resulted in a predicted probability of endoscopic improvement of $61.2 \pm 5.5 \%$ and $50.3 \pm 8.4 \%$. By increasing the dose to $10 \mathrm{mg} / \mathrm{kg}$, exposure doubled to 4910 [2431-9609] $\mathrm{mg} \times$ day/L and 3958 [1906-7981] $\mathrm{mg} \times$ day/L. Probabilities of endoscopic improvement also increased to $68.6 \pm 3.6 \%$ and $61.6 \pm 6.1 \%$.

Adapting the dose based on relevant covariates allowed more precise dosing, as between-population-variability can be taken into account. As can be seen in Figure 2, covariate-based MIPD resulted in the same median exposure as $10 \mathrm{mg} / \mathrm{kg}$ dosing, at a reduced variability (4895 [2661-8522] $\mathrm{mg} \times$ day/L and 3933 [2123-7045] $\mathrm{mg} \times$ day $/ \mathrm{L}$, for baseline Mayo endoscopic subscore 2 and 3, respectively). Dose adaptation based on the trough concentration measured at day 14 (Bayesian forecasting) further reduced this variability (5095 [3683-6879] $\mathrm{mg} \times$ day $/ \mathrm{L}$ and 4125 [3056-5431] $\mathrm{mg} \times$ day $/ \mathrm{L}$ ). The probability of endoscopic improvement followed a similar pattern, with similar mean probabilities across $10 \mathrm{mg} / \mathrm{kg}$ dosing, covariate-based MIPD, and concentration-based MIPD. 

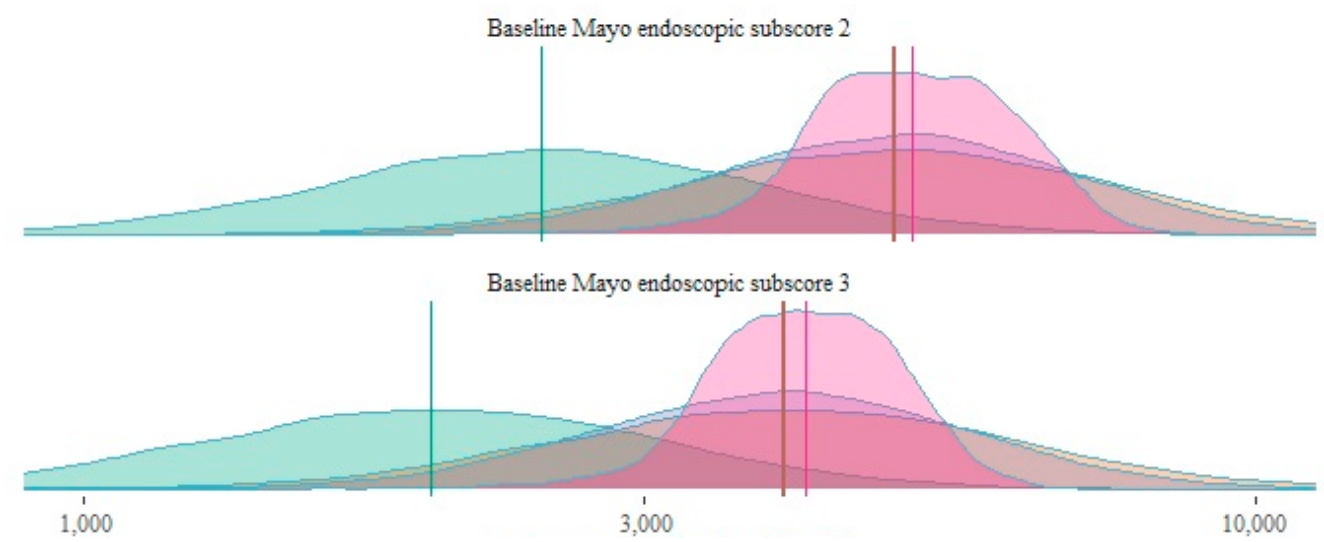

(a)
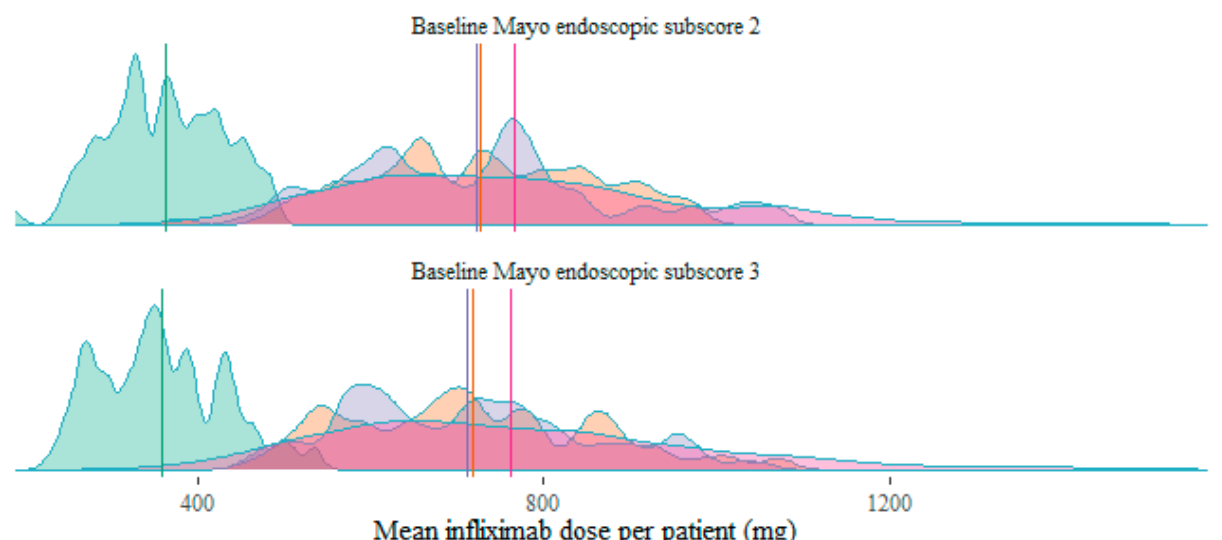

(b)

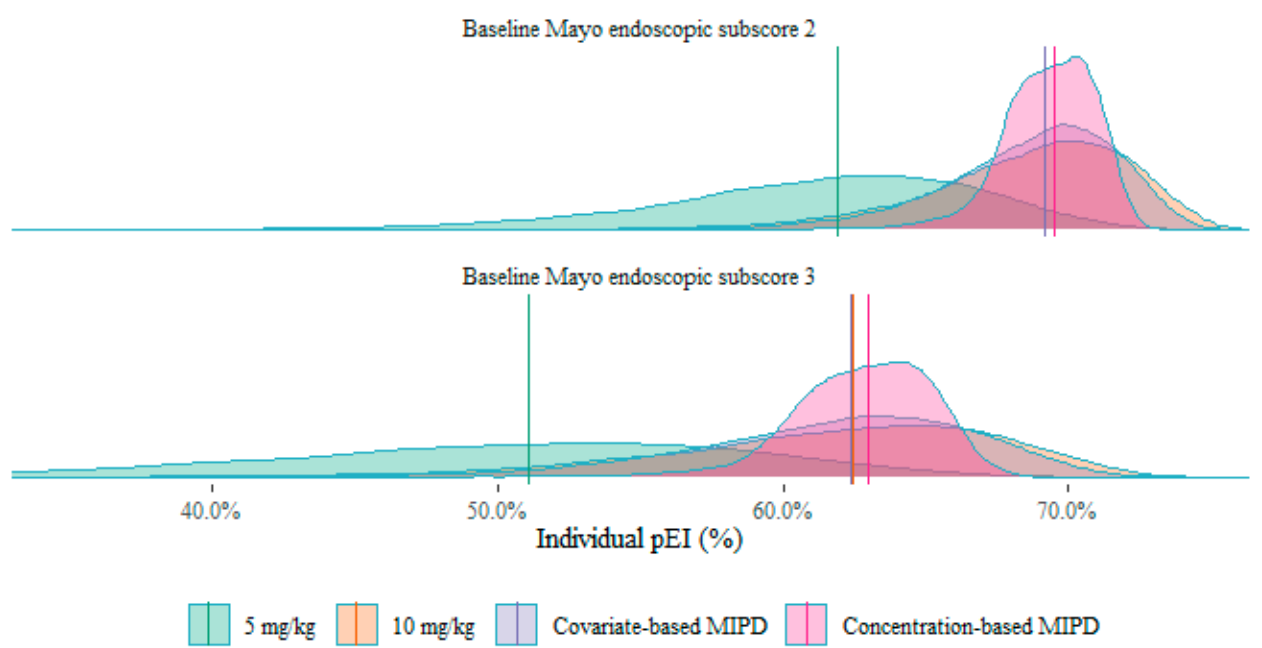

(c)

Figure 2. (a) Density plots of exposure in each of the four dosing scenarios, per baseline Mayo endoscopic subscore. Vertical lines show median exposure per scenario. (b) Density plots of the mean doses in each of the four dosing scenarios, per baseline Mayo endoscopic subscore. Vertical lines show overall mean dose per scenario. (c) Density plots of the individual probability of endoscopic improvement in each of the four dosing scenarios, per baseline Mayo endoscopic subscore. Vertical lines show overall mean pEI per scenario. CAUC, cumulative area under the curve; MIPD, model-informed precision dosing; pEI, probability of endoscopic improvement. 


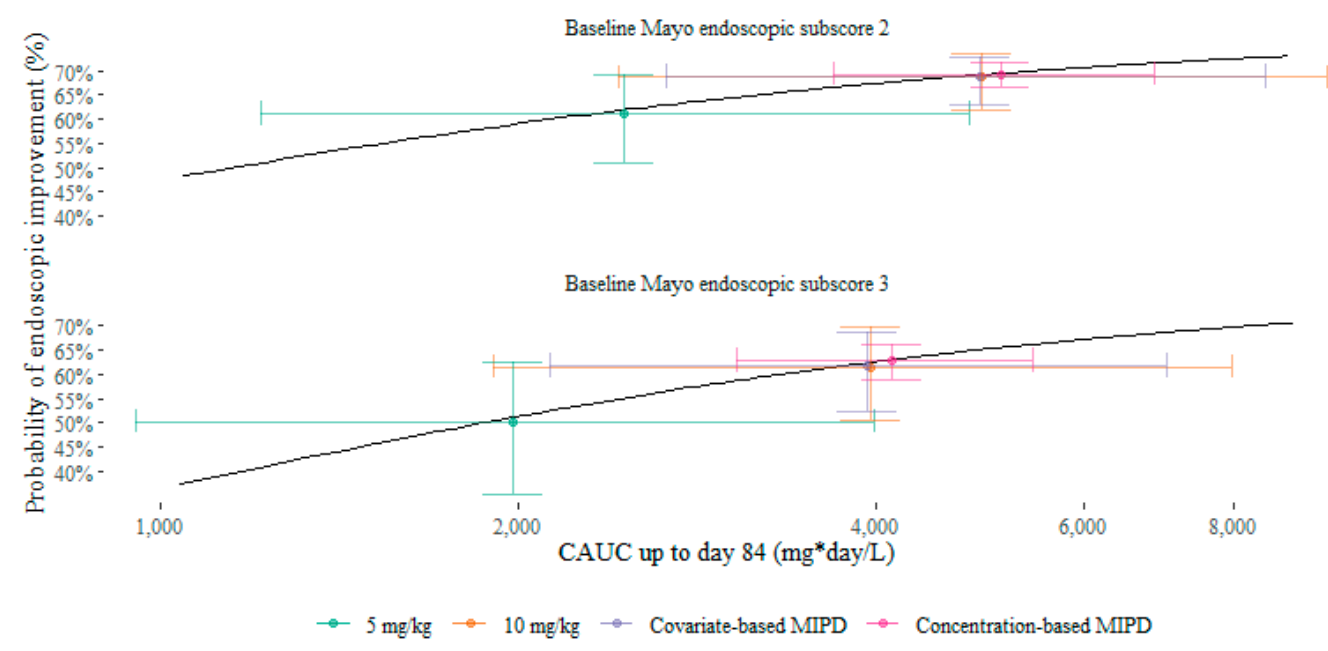

Figure 3. Predicted mean probability of endoscopic improvement versus median exposure, with $90 \%$ prediction interval in each scenario, per baseline Mayo endoscopic subscore. Black lines show model-predicted response. CAUC, cumulative area under the curve; MIPD, model-informed precision dosing.

\subsection{Dosing Simulations: Drug Consumption}

Looking at the average infliximab dose used per patient (see also Figure 2), $5 \mathrm{mg} / \mathrm{kg}$ dosing resulted in $1084 \mathrm{mg}$ per patient, and $10 \mathrm{mg} / \mathrm{kg}$ dosing doubled the dose usage to $2168 \mathrm{mg}$ per patient. Covariate-based MIPD used an average of $2151 \mathrm{mg}$ per patient. Concentration-based MIPD used, at average, $2293 \mathrm{mg}$ per patient.

\subsection{Sensitivity Analysis}

The analysis presented above assumed an $E_{\max }$ plateau of $78 \%$ for the probability of transitioning from a Mayo endoscopic subscore of 2 (moderate disease severity) to a Mayo endoscopic subscore of 0 or 1 (endoscopic improvement). This plateau benefited MIPD, as overexposed patients were dose-reduced without significantly reducing the probability of endoscopic improvement, while underexposed patients were dose-increased, thereby significantly increasing the probability of endoscopic improvement.

Repeating our simulation study with higher values for $E_{\max , 2 \rightarrow 1 / 0}$ decreased this benefit, further favoring $10 \mathrm{mg} / \mathrm{kg}$ dosing, as is illustrated in Figure 2. Other parameter combinations at $\Delta 2 L L=3.84$, as well as for the base model $(\Delta 2 L L=0)$, consistently showed less favorable results for MIPD.

At $E_{\max , 3 \rightarrow 2}-E_{\max , 2 \rightarrow 1 / 0}$ of $92.6-100 \%$, the probability of endoscopic improvement for $10 \mathrm{mg} / \mathrm{kg}$ dosing was 77.0\% [62.7-86.5\%] and 65\% [48.1-76.7\%], for baseline Mayo endoscopic subscore 2 and 3, respectively, at an average drug consumption of $2168 \mathrm{mg}$ per patient. Bayesian forecasting resulted in a probability of endoscopic improvement of $77.6 \%$ [71.7-82.3\%] and 65.8\% [59.4-70.9\%], for baseline Mayo endoscopic subscore 2 and 3, at an average drug consumption of $2293 \mathrm{mg}$ per patient.

\section{Discussion}

In this study, we compared four possible dosing scenarios for infliximab induction therapy in patients with UC: $5 \mathrm{mg} / \mathrm{kg}$ weight-based dosing (label dosing), and three dosing strategies with increased exposure: $10 \mathrm{mg} / \mathrm{kg}$ weight-based dosing, covariatebased MIPD, and concentration-based MIPD, all with unchanged timing of the infusions (day 0,14 , and 42 ). The $10 \mathrm{mg} / \mathrm{kg}$ dosing scenario was predicted to significantly improve endoscopic outcomes as compared to $5 \mathrm{mg} / \mathrm{kg}$ dosing. By design, MIPD (based on either covariates or the day 14 trough concentration) resulted in the same median exposure $\left(\mathrm{AUC}_{\mathrm{d} 84}\right)$ and, consequently, the same mean probability of endoscopic improvement as observed in the $10 \mathrm{mg} / \mathrm{kg}$ dosing scenario. MIPD was predicted to successfully adapt individual patient doses, reducing the interindividual variability in infliximab exposure 
and, with it, the probability of endoscopic improvement, thereby providing "more equal" chances of endoscopic remission to all patients. Surprisingly, it did so at a higher average drug consumption per patient. Underexposed patients indeed received a relative dose increase, while overexposed patients received a relative dose decrease. However, this is a non-zero sum, as, e.g., $10 \mathrm{mg} \times 2+10 \mathrm{mg} \times 0.5>10 \mathrm{mg}+10 \mathrm{mg}$. Therefore, our simulation study showed improved outcomes under $10 \mathrm{mg} / \mathrm{kg}$ dosing as compared to $5 \mathrm{mg} / \mathrm{kg}$ dosing and showed additional benefit of MIPD over $10 \mathrm{mg} / \mathrm{kg}$ for reducing variability in exposure and efficacy between patients; however, at a higher direct drug cost. Performing MIPD may thus require a willingness to "pay for equality" amongst patients [22]. Consequently, we may consider shifting focus from outcome rates at the population level (the traditional industry perspective) to outcome chances at the individual patient level. It is at the individual patient level that MIPD may show value. Since the majority of patients attain the target under empirical dosing, it is important that future MIPD studies are restricted to vulnerable populations, such as patients with acute severe ulcerative colitis [23].

The simulations described in this work were based on a previously established popPK model and exposure-response model of infliximab [18]. These models described the relation between the infliximab dose and exposure, and the $\mathrm{AUC}_{\mathrm{d} 84}$ and the probability of endoscopic improvement at day 84 , respectively. The models were established on a dataset of 204 patients with moderate-to-severe UC. Since the majority of the infliximab doses in the original cohort were $5 \mathrm{mg} / \mathrm{kg}$ (approximately $90 \%$ ), and only about $10 \%$ of the doses were $10 \mathrm{mg} / \mathrm{kg}$, it should be noted that the exposure-response model was built on a relatively limited range of exposures. The exposures simulated in the present work exceed this range. However, this weakness was mitigated by a thorough analysis of exposure-response model parameter confidence intervals and likelihood profiling, and a sensitivity analysis. Our findings hold throughout the full range of probable model parameter values.

The exposure-response model assumes a causal effect between exposure and response. Previous clinical studies have indeed found a correlation between low trough concentrations and primary nonresponse to anti-TNF $\alpha$ therapy [24]. However, the causality assumed in our exposure-response model was never established in clinical studies. In light of this, time-varying disease-related covariates may instead be simulated in a joint model, avoiding potential underestimation of exposure at higher doses and reduced disease severity. Further research is needed to definitively establish whether non-response at low trough concentrations is due to mechanistic failure (pharmacodynamic [PD] failure) or underexposure (PK failure), as others have attempted to model this distinction $[25,26]$. Underexposure can be resolved through dose increase, while the mechanistic failure suggests switching to a different drug with another mechanism of action. A more fine-grained model of continuous endpoints may distinguish between PK and PD failure.

High exposure to infliximab may pose safety concerns. The $10 \mathrm{mg} / \mathrm{kg}$ dosing may result in very high exposures, which were predicted in the present study to be beneficial to patients. In reality, these highly exposed patients may present with adverse drug reactions such as infections, especially in the elderly, and MIPD may benefit these patients by reducing toxicity [27-29].

Our findings seemingly contradict the pivotal ACT 1 and 2 trials [1], which showed no significant difference between $5 \mathrm{mg} / \mathrm{kg}$ and $10 \mathrm{mg} / \mathrm{kg}$ in endoscopic improvement rates on day 56 of therapy. Nevertheless, in the post-hoc PK-PD analysis of ACT 1 and 2, the exposure-response relationship has been established [6]. It would be worthwhile to repeat the presented modeling and simulation exercise, including the data from these pivotal trials. Notwithstanding these results, clinical trials are currently underway, evaluating an intensified induction regimen of $10 \mathrm{mg} / \mathrm{kg}$ [30].

MIPD of infliximab has been implemented in clinical practice mainly in tertiary care centers, however, even there, the confidence in MIPD is crumbling as the results of the landmark TAXIT, TAILORIX, and NOR-DRUM trials do not live up to expectations [12,14,31]. Our research showed that in silico simulations are a low-cost alternative to these clinical 
studies. Nevertheless, the translation of findings from a virtual trial into the real world may be challenged by noise due to, for example, sampling and measurement errors, rounding of doses and dosing intervals, etc. [32].

MIPD is classically used to improve the probability of target attainment, with the target window defined by efficacy and toxicity. In this context, efficacy is ever-increasing with higher exposures, while a dose increase is largely limited by cost rather than toxicity. It may be interesting to quantify the effect of infliximab as quality-adjusted life years (QALY) instead, allowing a direct comparison to increased cost and a straightforward optimization of QALY / cost.

In summary, we performed simulations to illustrate and predict the impact of three dosing strategies for increasing infliximab exposure during induction therapy as compared to $5 \mathrm{mg} / \mathrm{kg}$ weight-based label dosing, thereby improving the probability of endoscopic improvement. The use of $10 \mathrm{mg} / \mathrm{kg}$ dosing was indeed predicted to improve the probability of endoscopic improvement to $65.1 \%$ at an average drug consumption of $2168 \mathrm{mg}$ per patient during induction therapy. Individualized dose adaptation could maintain the same mean probability of endoscopic improvement while reducing variability between individual patients. Although MIPD showed benefit for reducing variability in exposure and efficacy between patients, this comes at a higher direct drug cost as compared to $10 \mathrm{mg} / \mathrm{kg}$ weight-based dosing.

Supplementary Materials: The following are available online at https:/ /www.mdpi.com/article/10 .3390/pharmaceutics13101623/s1, Figure S1: Prediction-corrected visual predictive check of the original population pharmacokinetic model, Figure S2. Log-likelihood surface for the exposure-response model, Table S1. Parameter estimates of the original and adapted population pharmacokinetic models.

Author Contributions: Conceptualization, R.F., T.B. and E.D.; Data curation, P.D., M.F., S.V. and E.D.; Formal analysis, R.F. and Z.W.; Funding acquisition, E.D.; Investigation, R.F., Z.W. and E.D.; Methodology, R.F., Z.W. and E.D.; Project administration, E.D.; Resources, P.D., M.F., S.V. and E.D.; Software, R.F.; Supervision, T.B. and E.D.; Validation, R.F., T.B. and E.D.; Visualization, R.F., Z.W. and E.D.; Writing—original draft, R.F., Z.W. and E.D.; Writing—review \& editing, T.B., P.D., M.F. and S.V. All authors have read and agreed to the published version of the manuscript.

Funding: This research was funded by the Research Foundation-Flanders (FWO), Belgium: T.B. received a TBM grant (grant number T003117N), P.D. received a TBM grant (grant number T003716N), M.F. is a Senior Clinical Investigator, and E.D. is a postdoctoral research fellow (grant number: 12X9420N).

Institutional Review Board Statement: The study was conducted according to the guidelines of the Declaration of Helsinki and approved by the Ethics Committee Research of UZ/KU Leuven (3000, IBD Biobank; B322201213950/S53684)."

Informed Consent Statement: Informed consent was obtained from all subjects involved in the study.

Data Availability Statement: The data presented in this study are available in the research article and supplementary material here.

Acknowledgments: We acknowledge Vera Ballet for an excellent job in maintaining the Leuven IBD patient database; Griet Compernolle, Sophie Tops, Els Brouwers, and Miet Peeters for performing the infliximab serum concentration measurements; and Pieter Annaert for the guidance and management of student R.F.

Conflicts of Interest: R.F. performed consulting work for Janssen Pharmaceutica on compounds not related to Remicade in the employ of SGS Exprimo NV. T.B. is a paid employer of BioNotus. M.F. received research grant from AbbVie, Amgen, Biogen, Janssen, Pfizer, and Takeda; speakers fee from Abbvie, Amgen, Biogen, Boehringer-Ingelheim, Falk, Ferring, Janssen, Lamepro, MSD, Mylan, Pfizer, Sandoz, Takeda and Truvion Healthcare; consultancy fee from Abbvie, Boehringer-Ingelheim, Celltrion, Janssen, Lilly, Medtronic, MSD, Pfizer, Sandoz, Takeda and Thermo Fisher. S.V. received financial support for research from AbbVie, J\&J, Pfizer, and Takeda; consulting and/or speaking fees from AbbVie, Arena Pharmaceuticals, Avaxia, Boehringer Ingelheim, Celgene, Falk Pharma, Ferring, Galapagos, Genentech-Roche, Gilead, Hospira, Janssen, Mundipharma, MSD, Pfizer, Prodigest, Progenity, Prometheus, Robarts Clinical Trials, Second Genome, Shire, Takeda, Theravance, and 
Tillots Pharma AG. E.D. received consultancy fees from argenx and Janssen (all fees paid to the University). Z.W. and P.D. declare no conflict of interest. The funders had no role in the design of the study; in the collection, analyses, or interpretation of data; in the writing of the manuscript, or in the decision to publish the results.

\section{References}

1. Rutgeerts, P.; Sandborn, W.J.; Feagan, B.G.; Reinisch, W.; Olson, A.; Johanns, J.; Travers, S.; Rachmilewitz, D.; Hanauer, S.B.; Lichtenstein, G.R.; et al. Infliximab for Induction and Maintenance Therapy for Ulcerative Colitis. N. Engl. J. Med. 2005, 353, 2462-2476. [CrossRef]

2. $\quad$ Brandse, J.F.; Mathôt, R.A.; van der Kleij, D.; Rispens, T.; Ashruf, Y.; Jansen, J.M.; Rietdijk, S.; Löwenberg, M.; Ponsioen, C.Y.; Singh, S.; et al. Pharmacokinetic Features and Presence of Antidrug Antibodies Associate With Response to Infliximab Induction Therapy in Patients With Moderate to Severe Ulcerative Colitis. Clin. Gastroenterol. Hepatol. 2016, 14, 251-258.e2. [CrossRef] [PubMed]

3. Seow, C.H.; Newman, A.; Irwin, S.P.; Steinhart, A.H.; Silverberg, M.S.; Greenberg, G.R. Trough serum infliximab: A predictive factor of clinical outcome for infliximab treatment in acute ulcerative colitis. Gut 2010, 59, 49-54. [CrossRef]

4. Papamichael, K.; Van Stappen, T.; Vande Casteele, N.; Gils, A.; Billiet, T.; Tops, S.; Claes, K.; Van Assche, G.; Rutgeerts, P.; Vermeire, S.; et al. Infliximab Concentration Thresholds During Induction Therapy Are Associated With Short-term Mucosal Healing in Patients With Ulcerative Colitis. Clin. Gastroenterol. Hepatol. 2016, 14, 543-549. [CrossRef] [PubMed]

5. $\quad$ Farkas, K.; Rutka, M.; Golovics, P.A.; Végh, Z.; Lovász, B.D.; Nyári, T.; Gecse, K.B.; Kolar, M.; Bortlik, M.; Duricova, D.; et al. Efficacy of infliximab biosimilar CT-P13 induction therapy on mucosal healing in ulcerative colitis. J. Crohns Colitis 2016, 10, 1273-1278. [CrossRef] [PubMed]

6. Adedokun, O.J.; Sandborn, W.J.; Feagan, B.G.; Rutgeerts, P.; Xu, Z.; Marano, C.W.; Johanns, J.; Zhou, H.; Davis, H.M.; Cornillie, F.; et al. Association between serum concentration of infliximab and efficacy in adult patients with ulcerative colitis. Gastroenterology 2014, 147, 1296-1307.e5. [CrossRef]

7. Arias, M.T.; Vande Casteele, N.; Vermeire, S.; de Buck van Overstraeten, A.; Billiet, T.; Baert, F.; Wolthuis, A.; Van Assche, G.; Noman, M.; Hoffman, I.; et al. A panel to predict long-term outcome of infliximab therapy for patients with ulcerative colitis. Clin. Gastroenterol. Hepatol. 2015, 13, 531-538. [CrossRef]

8. Kobayashi, T.; Suzuki, Y.; Motoya, S.; Hirai, F.; Ogata, H.; Ito, H.; Sato, N.; Ozaki, K.; Watanabe, M.; Hibi, T. First trough level of infliximab at week 2 predicts future outcomes of induction therapy in ulcerative colitis-results from a multicenter prospective randomized controlled trial and its post hoc analysis. J. Gastroenterol. 2016, 51, 241-251. [CrossRef]

9. Vande Casteele, N.; Jeyarajah, J.; Jairath, V.; Feagan, B.G.; Sandborn, W.J. Infliximab Exposure-Response Relationship and Thresholds Associated With Endoscopic Healing in Patients With Ulcerative Colitis. Clin. Gastroenterol. Hepatol. 2019, 17, 1814-1821. [CrossRef]

10. Vande Casteele, N.; Herfarth, H.; Katz, J.; Falck-Ytter, Y.; Singh, S. American Gastroenterological Association Institute Technical Review on the Role of Therapeutic Drug Monitoring in the Management of Inflammatory Bowel Diseases. Gastroenterology 2017, 153, 835-857. [CrossRef]

11. Harbord, M.; Eliakim, R.; Bettenworth, D.; Karmiris, K.; Katsanos, K.; Kopylov, U.; Kucharzik, T.; Molnár, T.; Raine, T.; Sebastian, S.; et al. Third European evidence-based consensus on diagnosis and management of ulcerative colitis. Part 2: Current management. J. Crohns Colitis 2017. [CrossRef]

12. Vande Casteele, N.; Ferrante, M.; Van Assche, G.; Ballet, V.; Compernolle, G.; Van Steen, K.; Simoens, S.; Rutgeerts, P.; Gils, A.; Vermeire, S. Trough concentrations of infliximab guide dosing for patients with inflammatory bowel disease. Gastroenterology 2015, 148, 1320-1329. [CrossRef] [PubMed]

13. Mitrev, N.; Vande Casteele, N.; Seow, C.H.; Andrews, J.M.; Connor, S.J.; Moore, G.T.; Barclay, M.; Begun, J.; Bryant, R.; Chan, W.; et al. Review article: Consensus statements on therapeutic drug monitoring of anti-tumour necrosis factor therapy in inflammatory bowel diseases. Aliment. Pharmacol. Ther. 2017, 46, 1037-1053. [CrossRef] [PubMed]

14. Syversen, S.W.; Goll, G.L.; Jørgensen, K.K.; Sandanger, Ø.; Sexton, J.; Olsen, I.C.; Gehin, J.E.; Warren, D.J.; Brun, M.K.; Klaasen, R.A.; et al. Effect of Therapeutic Drug Monitoring vs Standard Therapy During Infliximab Induction on Disease Remission in Patients With Chronic Immune-Mediated Inflammatory Diseases: A Randomized Clinical Trial. JAMA 2021, 325, 1744-1754. [CrossRef] [PubMed]

15. Wang, Z.; Dreesen, E. Therapeutic drug monitoring of anti-tumor necrosis factor agents: Lessons learned and remaining issues. Curr. Opin. Pharmacol. 2020, 55, 53-59. [CrossRef]

16. Keizer, R.J.; ter Heine, R.; Frymoyer, A.; Lesko, L.J.; Mangat, R.; Goswami, S. Model-Informed Precision Dosing at the Bedside: Scientific Challenges and Opportunities. CPT Pharmacomet. Syst. Pharmacol. 2018, 7, 785-787. [CrossRef] [PubMed]

17. Vermeire, S.; Dreesen, E.; Papamichael, K.; Dubinsky, M.C. How, When, and for Whom Should We Perform Therapeutic Drug Monitoring? Clin. Gastroenterol. Hepatol. 2019. [CrossRef]

18. Dreesen, E.; Faelens, R.; Van Assche, G.; Ferrante, M.; Vermeire, S.; Gils, A.; Bouillon, T. Optimising infliximab induction dosing for patients with ulcerative colitis. Br. J. Clin. Pharmacol. 2019, 85, 782-795. [CrossRef]

19. Ben-Horin, S.; Kopylov, U.; Chowers, Y. Optimizing anti-TNF treatments in inflammatory bowel disease. Autoimmun. Rev. 2014, 13, 24-30. [CrossRef] 
20. Sheiner, L.B. Analysis of pharmacokinetic data using parametric models. III. Hypothesis tests and confidence intervals. J. Pharmacokinet. Biopharm. 1986, 14, 539-555. [CrossRef]

21. Fidler, M.L.; Hallow, M.; Wilkins, J.; Wang, W. RxODE: Facilities for Simulating from ODE-Based Models 2021. R package version 1.1.0. Available online: https:/ /CRAN.R-project.org/package=RxODE (accessed on 20 August 2021).

22. Dreesen, E. New Tools for Therapeutic Drug Monitoring: Making Big Things out of Small Pieces. J. Crohns Colitis 2021. [CrossRef] [PubMed]

23. Battat, R.; Hemperly, A.; Truong, S.; Whitmire, N.; Boland, B.S.; Dulai, P.S.; Holmer, A.K.; Nguyen, N.H.; Singh, S.; Vande Casteele, N.; et al. Baseline Clearance of Infliximab Is Associated With Requirement for Colectomy in Patients With Acute Severe Ulcerative Colitis. Clin. Gastroenterol. Hepatol. 2021, 19, 511-518.e6. [CrossRef] [PubMed]

24. Ding, N.S.; Hart, A.; De Cruz, P. Systematic review: Predicting and optimising response to anti-TNF therapy in Crohn's disease-Algorithm for practical management. Aliment. Pharmacol. Ther. 2016, 43, 30-51. [CrossRef]

25. Dreesen, E.; Berends, S.; Laharie, D.; D’Haens, G.; Vermeire, S.; Gils, A.; Mathôt, R. Modelling of the relationship between infliximab exposure, faecal calprotectin and endoscopic remission in patients with Crohn's disease. Br. J. Clin. Pharmacol. 2020, 87, 106-118. [CrossRef] [PubMed]

26. Brekkan, A.; Lopez-Lazaro, L.; Yngman, G.; Plan, E.L.; Acharya, C.; Hooker, A.C.; Kankanwadi, S.; Karlsson, M.O. A Population Pharmacokinetic-Pharmacodynamic Model of Pegfilgrastim. AAPS J. 2018, 20, 91. [CrossRef]

27. Kantasiripitak, W.; Verstockt, B.; Alsoud, D.; Lobatón, T.; Thomas, D.; Gils, A.; Vermeire, S.; Ferrante, M.; Dreesen, E. The effect of aging on infliximab exposure and response in patients with inflammatory bowel diseases. Br. J. Clin. Pharmacol. 2021. [CrossRef]

28. Bejan-Angoulvant, T.; Ternant, D.; Daoued, F.; Medina, F.; Bernard, L.; Mammou, S.; Paintaud, G.; Mulleman, D. Brief Report: Relationship Between Serum Infliximab Concentrations and Risk of Infections in Patients Treated for Spondyloarthritis. Arthritis Rheumatol. 2017, 69, 108-113. [CrossRef]

29. Landemaine, A.; Petitcollin, A.; Brochard, C.; Miard, C.; Dewitte, M.; Le, E.; Grainville, T.; Bellissant, E.; Siproudhis, L.; Bouguen, G. Cumulative Exposure to Infliximab, But Not Trough Concentrations, Correlate With Rate of Infection. Clin. Gastroenterol. Hepatol. 2020. [CrossRef] [PubMed]

30. NIH U.S. Natial Library of Medicine ClinicalTrials.gov. Optimising Infliximab Induction Therapy for Acute Severe Ulcerative Colitis (PREDICT-UC). Available online: https:/ / clinicaltrials.gov/ct2/show / NCT02770040 (accessed on 16 July 2021).

31. D’Haens, G.; Vermeire, S.; Lambrecht, G.; Baert, F.; Bossuyt, P.; Pariente, B.; Buisson, A.; Bouhnik, Y.; Filippi, J.; vander Woude, J.; et al. Increasing Infliximab Dose Based on Symptoms, Biomarkers, and Serum Drug Concentrations Does Not Increase Clinical, Endoscopic, and Corticosteroid-Free Remission in Patients With Active Luminal Crohn's Disease. Gastroenterology 2018, 154, 1343-1351.e1. [CrossRef] [PubMed]

32. Alihodzic, D.; Broeker, A.; Baehr, M.; Kluge, S.; Langebrake, C.; Wicha, S.G. Impact of Inaccurate Documentation of Sampling and Infusion Time in Model-Informed Precision Dosing. Front. Pharmacol. 2020, 11, 1-12. [CrossRef] 